\title{
Die Lusiade de Luis de Camões, entre tradition et modernité
}

\section{Amélia Costa da Silva}

\section{(2) OpenEdition}

1 Journals

Édition électronique

URL : http://journals.openedition.org/rbnu/707

DOI : 10.4000/rbnu.707

ISSN : 2679-6104

Éditeur

Bibliothèque nationale et universitaire de Strasbourg

Édition imprimée

Date de publication : 1 novembre 2017

Pagination : 92-95

ISBN : 9782859230678

ISSN : 2109-2761

\section{Référence électronique}

Amélia Costa da Silva, "Die Lusiade de Luis de Camões, entre tradition et modernité », La Revue de la BNU [En ligne], 16 | 2017, mis en ligne le 01 juillet 2019, consulté le 23 décembre 2020. URL : http:// journals.openedition.org/rbnu/707 ; DOI : https://doi.org/10.4000/rbnu.707

\section{(c) (i) (8)}

La Revue de la BNU est mise à disposition selon les termes de la Licence Creative Commons Attribution - Pas d'Utilisation Commerciale - Partage dans les Mêmes Conditions 4.0 International. 


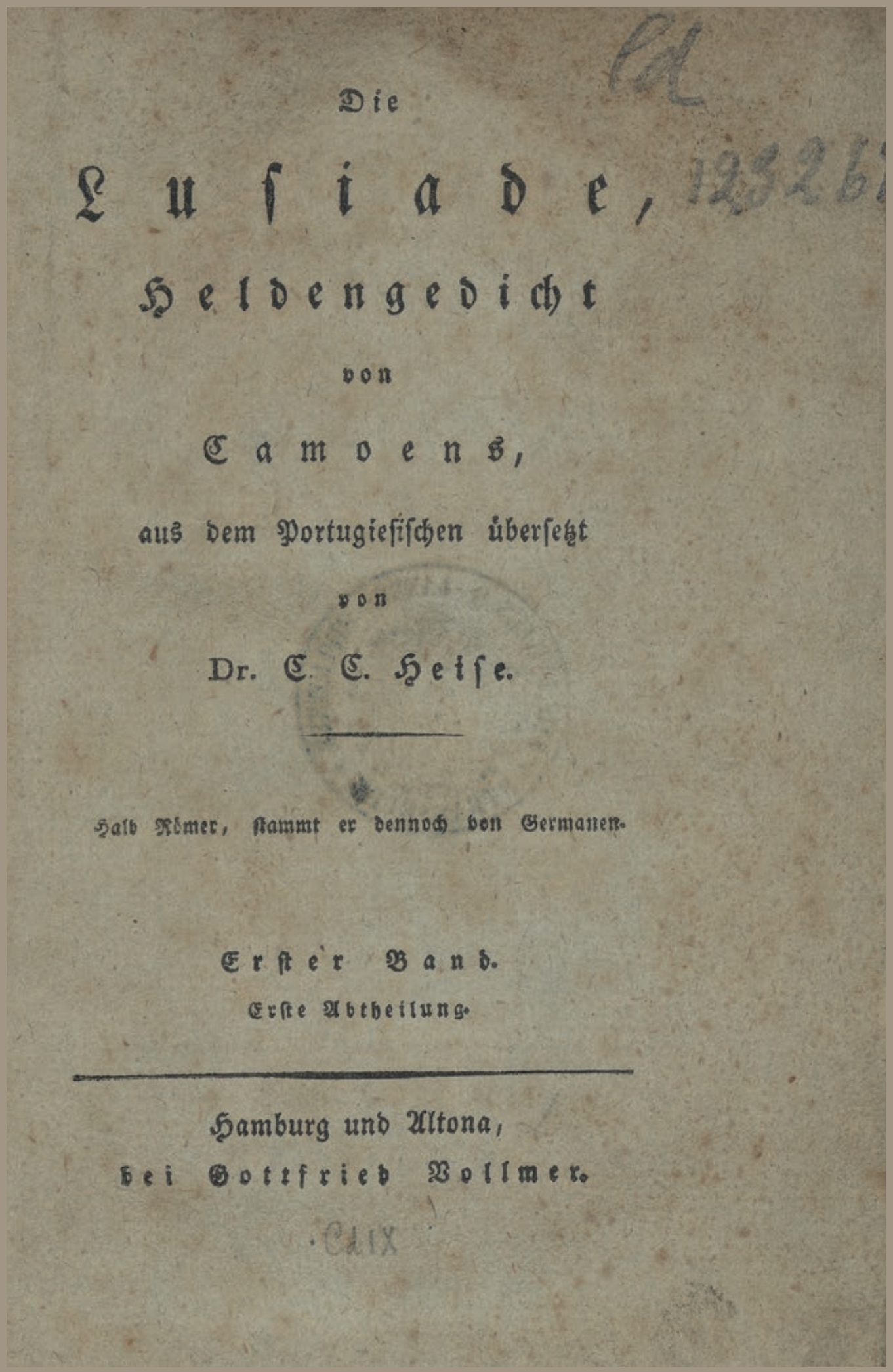

Die Lusiade, Heldengedicht von Camoens, aus dem Portugiesischen übersetzt von Dr. C. C. Heise, Hamburg und Altona, bei Gottfried Vollmer, [1806-1807] 


\section{PORTUGAL \\ DIE LUSIADE DE LUIS DE CAMÕES, ENTRE TRADITION ET MODERNITÉ \\ PAR AMÉLIA COSTA DA SILVA}

« Le fond [des Lusiades] n'est ni une guerre, ni une querelle de héros, ni le monde en armes pour une femme ; c'est un nouveau pays découvert à l'aide de la navigation... »

Voltaire, Essai sur la poésie épique

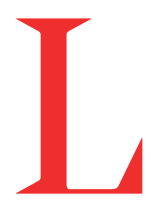

e texte ici présenté démontre bien avec quel engouement l'Europe des Lumières a su accueillir une épopée qui, beaucoup plus par son fond que par sa forme, en entremêlant création poétique et récit historique, est le portrait de l'homme à la conquête du monde. C'est son grand poème épique qui assure à Luís de Camões (vers 1524-1580) sa primauté dans la littérature de son pays et dans la poésie de la Renaissance, dans ce dialogue constant qui résume l'humanisme portugais, tourné vers la redécouverte d'un passé où s'associent racines mythiques et poétiques, mais plongé également dans l'excitant engouement des découvertes, du rêve européen de l'avenir, sur des mers jamais encore parcourues par des navires.
En Allemagne, dans le sillage de plusieurs traductions partielles réalisées souvent par des figures illustres, comme le philosophe Johann Gottlieb Fichte qui, en 1810, publia dans la revue Pantheon une traduction du célèbre épisode d'Inês de Castro, ce fut un médecin dont le nom était jusque-là inconnu des cercles littéraires et érudits, Carl Christian Heise, qui publia à Hambourg, sans indication de date mais très probablement en 1806, la première traduction complète, en " ottava rima ", du poème de Camões. Bien que d'autres traductions plus largement diffusées et faites par des traducteurs plus expérimentés aient été publiées immédiatement après, celle de Heise, Die Lusiade, Heldengedicht von Camoens, au-delà du fait d'être la première et en étant le fruit d'un travail éditorial plus modeste, fait preuve d'une grande attention à la cadence rythmique du poème et d'un souci admirable de respect et de fidélité au texte de départ. La traduction de Heise participe donc d'un enthousiasme général, celui de l'homme des Lumières qui se reconnaît dans une forme de quête de la modernité.

Les Lusiades sont les fils de Lusus, personnage mythique, fils de Bacchus, et l'épopée homonyme de 
Camões, achevée probablement en 1556 mais publiée en 1572 à Lisbonne, après le retour du poète d'Orient au bout de dix-sept ans de voyages, d'aventures et de misères, célèbre les hauts faits de la grande épopée maritime du peuple portugais et sera le blason et le symbole le plus expressif - le plus parlant - du premier empire de l'Occident. Organisés en dix chants et avec 1102 strophes composées en "ottava rima », au long de 8816 vers, Les Lusiades chantent l'expérience nautique portugaise au cours des soixante-dix ans séparant l'arrivée de la première escadre portugaise aux Indes et l'achèvement du poème. Le récit des découvertes géographiques et de la gloire maritime des Portugais est livré en partie par Camões lui-même, mais également par les voix de nombreux personnages, comme Jupiter, le vieillard du Restelo, la nymphe Téthys ou le navigateur Vasco de Gama, celui qui, empruntant la route de Bartholomé Diaz jusqu'au cap des Tempêtes, a abordé aux Indes en 1498. Cependant, quand s'ouvre le poème, les navigateurs ont déjà parcouru un long chemin - « Déjà ils naviguaient sur le large Océan, écartant les flots tourmentés " -, le cap de Bonne-Espérance a été doublé et le navire a réussi à échapper aux récifs et aux attaques de l'ennemi. Cette aventure singulière, nourrie des exploits et de l'ambition des Lusitaniens, le lecteur le sait dès le début, a divisé même les dieux de l'Olympe - apparente contradiction puisque bien que l'épopée exalte sur le fond les valeurs du catholicisme, ce sont les dieux païens qui interviennent dans l'entreprise portugaise, expression claire d'une vision du monde et des valeurs esthétiques chères à la Renaissance : Bacchus est le gardien des mystères de l'Inde et est, de ce fait, l'ennemi des Portugais tandis que Mars, et surtout Vénus, les protègent car le courage et l'amour sont inséparables.

Dans le récit, les marins arrivent à Melinda où le sultan, comme Didon accueillant Enée, prie Vasco de Gama de raconter ses aventures. Le navigateur obéit et dit toute l'histoire de son peuple, celle qui est déjà fixée par les chroniques et apparaît dans des tableaux et tapisseries. S'enchaîne ensuite l'évocation de plusieurs épisodes comme celui de l'adieu à Belém ou la rencontre du géant Adamastor, symbole des écueils, qui prédit aux marins les naufrages à venir. Arrivés enfin à Calicut, ils voient se succéder de nombreuses péripéties avec les peuples autochtones. Cependant, la véritable récompense pour leurs longues épreuves, les Portugais l'auront uniquement dans le voyage du retour : Vénus décide de couronner les travaux et le courage des marins au moyen de l'île des Amours, lieu paradisiaque et de sensualité où ils seront accueillis par les plus belles nymphes - récompense surhumaine, donc, pour leurs efforts et leur courage surhumains. Sur l'île aura également lieu la révélation de la destinée des Portugais, annoncée par Téthys à Gama, et la contemplation par ce dernier de « la machine du monde ", véritable maquette de l'univers selon le modèle géocentrique de Ptolémée. L'achèvement de l'aventure est ainsi l'écho d'une certitude : l'homme a désormais pris possession de la terre et de la mer.

En Camões, ses contemporains n'ont vu qu'un confrère moins doué, que quelques querelles et indiscrétions avaient privé de toute sorte de succès - «Mes fautes, un mauvais sort, l'amour ardent / S'étaient ligués dans le but de me perdre ", confie-t-il dans un des sonnets de son œuvre lyrique, publiée seulement après sa mort. Luís de Camões appartenait à une famille galicienne établie au Portugal au $14^{\mathrm{e}}$ siècle et fut, selon ses biographes, très probablement étudiant à Coimbra. Il sut y développer sa culture littéraire et fréquenta les milieux de la cour, où son esprit belliqueux et quelques dangereuses passions amoureuses lui apportèrent peu de succès littéraire et de nombreuses désillusions. Des exils surtout en Afrique, où il perdit l'œil droit, se succèdent jusqu'au jour où, en 1553 - échappatoire ou bannissement ? - il s'embarque de Lisbonne vers Le Cap, du Cap au Mozambique, du Mozambique à Goa, là où s'arrêtait le voyage de Gama, son héros, pour continuer ensuite - mission ou exil ? - jusqu'à Macao où on lui a attribué des fonctions administratives. Il y est mis aux arrêts, renvoyé à Goa pour se justifier mais est le seul survivant d'un naufrage à l'embouchure du Mékong. Du désastre, il n'aurait sauvé que le manuscrit de son poème. À Goa et sans argent pour rentrer au Portugal, il est obligé de faire le voyage du retour en deux étapes, avec un séjour de deux ans au Mozambique. En 1570, il arrive enfin dans une Lisbonne frappée par une épidémie de peste. L'année suivante, il obtient privilège, publication et même pension du jeune roi Sébastien pour la publication de ses Lusiades, qui paraîtront en 1572 et lui seront dédiés. En 1578 a lieu le désastre d'Alcazar Kébir, le jeune roi meurt avec presque toute 
son armée, et en 1580, au moment de la mort du poète, l'Espagne envahit le Portugal que Philippe II revendique par droit d'héritage. L'annexion durera soixante ans et c'est pendant cette période que le poème de l'aventure maritime des Portugais nourrira un peuple asservi et sera le rappel de ses exploits passés.

L'épopée camonéenne est le reflet de la vie de dérive d'un poète pour qui chanter l'aventure de la découverte du monde ne suffit pas : il faut également la vivre. De cette expérience est né son long poème, extraordinairement sauvé des eaux. Les mers de Camões seront la scène sur laquelle, pendant des siècles, joueront plusieurs peuples européens, mais la grande leçon des Lusiades, outre leur beauté et leur importance historique diffusées en Europe grâce au travail de leurs traducteurs, est peut-être celle de l'importance du rêve et de l'action dans la découverte de nouveaux horizons et dans l'élaboration de nouvelles images du monde. 